\title{
Evaluation of the effectiveness of iodine prophylaxis in Poland based on over 20 years of observations of iodine supply in school-aged children in the central region of the country
}

\author{
Arkadiusz Zygmunt ${ }^{1,2}$, Zbigniew Adamczewski ${ }^{1,2}$, Katarzyna Wojciechowska-Durczynska ${ }^{1,2}$, \\ Kinga Krawczyk-Rusiecka ${ }^{1,2}$, Ewa Bieniek ${ }^{1}$, Magdalena Stasiak ${ }^{1}$, Agnieszka Zygmunt ${ }^{3}$, \\ Krystian Purgat ${ }^{4}$, Robert Zakrzewski ${ }^{4}$, Jan Brzezinski ${ }^{1}$, Malgorzata Karbownik-Lewinska ${ }^{1,5}$, \\ Andrzej Lewinski ${ }^{1,2}$
}

${ }^{1}$ Department of Endocrinology and Metabolic Diseases, Polish Mother's Memorial
Hospital - Research Institute, Lodz, Poland
${ }^{2}$ Department of Endocrinology and Metabolic Diseases, Medical University of Lodz,
Lodz, Poland
${ }^{3}$ Department of Paediatric Rheumatology, Medical University of Lodz, Lodz, Poland
${ }^{4}$ Department of Environmental Chemistry, University of Lodz, Lodz, Poland
${ }^{5}$ Department of Oncological Endocrinology, Medical University of Lodz, Lodz, Poland

Submitted: 6 February 2018

Accepted: 22 March 2018

Arch Med Sci 2019; 15 (6): 1468-1474

DOI: https://doi.org/10.5114/aoms.2018.76150

Copyright (c) 2018 Termedia \& Banach

\section{Abstract}

Introduction: Due to the mild-to-moderate iodine deficiency in Poland, in 1997 iodine prophylaxis based on obligatory salt iodization was introduced. We attempted to evaluate the effectiveness of such prophylaxis, based on over 20 years of observations of iodine supply in school-aged children in Opoczno district (Central Poland).

Material and methods: A group of 603 children (316 girls and 287 boys), aged 6-14, was examined at 4 time points: in the years 1994, 1999, 2010 and 2016. The children were tested for urine iodine concentration (UIC) and in each child the thyroid volume was measured ultrasonographically. Results: The median UIC in $1994(45.5 \mu \mathrm{g} / \mathrm{l})$ indicated moderate iodine deficiency, while after introducing prophylaxis it corresponded to adequate values $(1999$ - $101.1 \mathrm{\mu g} / \mathrm{l}, 2010$ - $100.6 \mathrm{\mu g} / \mathrm{l}, 2016$ - $288.3 \mathrm{\mu g} / \mathrm{l})$; however, the last value was higher than the previous two. The thyroid size, assessed by ultrasonography and presented as volume/body surface area (V/BSA), in 1994 was $6.55 \times 10^{-6} \mathrm{~m}$; this value was higher than at other time points $\left(2.73 \times 10^{-6} \mathrm{~m}\right.$ in $1999,2.73 \times 10^{-6} \mathrm{~m}$ in 2010 , and $2.70 \times 10^{-6} \mathrm{~m}$ in 2016). Conclusions: lodine prophylaxis has proved effective in eliminating iodine deficiency. In recent years, the diversification of iodine sources, despite the reduction of salt consumption, has led to an increase in median UIC to values close to the upper limit of UIC, accepted as normal. Further increase in iodine supply may be unfavourable for health; therefore constant monitoring of iodine prophylaxis is required.

Key words: goitre, thyroid volume, urine iodine.
Corresponding author: Prof. Andrzej Lewinski

Department of Endocrinology and Metabolic Diseases Medical University of Lodz 281/289 Rzgowska St 93-338 Lodz, Poland Phone: +48 422711141 Fax: +48 42 2711140 E-mail: alewin@csk.umed. lodz.pl 


\section{Introduction}

Like most European countries, Poland is located in a naturally iodine-deficient area [1]. Based on research conducted in the 1980 s, this region was classified as an area of mild-to-moderate iodine deficiency [2]. These data were the starting point for introducing actions to ensure proper iodine supply [3].

In 1997, the model of iodine prophylaxis based on consumption of iodized salt, which should contain $30 \pm 10 \mathrm{mg} \mathrm{KI} / \mathrm{kg}$ of $\mathrm{NaCl}$ [4] or, since 2002, 39 $\pm 13 \mathrm{mg} \mathrm{KIO} / \mathrm{kg}$ of $\mathrm{NaCl}$, was introduced in Poland [5]. This model is still being continued. Although $\mathrm{KIO}_{3}$ is a more persistent compound, some experimental studies suggest that $\mathrm{KI}$ may provide more effective iodine prophylaxis than $\mathrm{KIO}_{3}[6]$.

Since then, the political and economic situation of Poland has also changed. Poland became a member of the European Union (in 2004), which was synonymous with the opening of the borders (common market) to the flow of goods, capital, services and people (Schengen area - since 2007). Political and economic changes have been followed by changes in the way of life. The population began to care about a "healthy" lifestyle, which resulted, among other things, in limiting dietary salt intake.

The aim of the study was to evaluate the effectiveness of iodine prophylaxis in Poland, based on over 20 years of observations of iodine supply, in a population of school-aged children in Opoczno.

\section{Material and methods}

The survey was conducted among children from a primary school in Opoczno, a town with a population of 23 thousand inhabitants, locat- ed in Central Poland, about $80 \mathrm{~km}$ southeast of Lodz. The study covered children from the entire Opoczno District attending the above-mentioned primary school.

A group of 603 randomly selected children (316 girls and 287 boys), Caucasian, born and growing up in Poland, aged 6-14, was examined. The study was conducted at 4 time points: in 1994, which was about 2.5 years before the introduction of iodine prophylaxis (88 children - 46 girls and 42 boys); in 1999 - 2.5 years after the introduction of iodine prophylaxis (207 children - 104 girls and 103 boys); in 2010 (170 children - 90 girls and 80 boys); and in 2016 (138 children - 76 girls and 62 boys); the two last time points were after Poland joined the European Union, and 13 and 19 years after the introduction of iodine prophylaxis, respectively.

The characteristics of the examined population are presented in Table I.

The study from 1994 was part of an international survey on iodine deficiency in Europe (Thyromobil Project) [7], while that from 1999 was part of a nationwide survey on the effectiveness of iodine prophylaxis in Poland [8]. Studies in 2010 [9] and 2016 were carried out within the project carried out by the Polish Mother's Memorial Hospital - Research Institute in Lodz. All studies were performed by employees of the same endocrinology department.

The Ethics Committee at the Polish Mother's Memorial Hospital - Research Institute, Lodz, Poland (No. 64/2016) approved the protocol for each study. Parents of all the children qualified for the experiment gave written consent for participation of their children in the study. The Ethics Committee approved the protocol.

Table I. The number of examined children in gender, age and body surface area (BSA) groups

\begin{tabular}{|c|c|c|c|c|c|c|c|c|c|c|c|}
\hline \multirow[t]{2}{*}{ Data } & \multicolumn{2}{|c|}{ All } & \multirow{2}{*}{$\begin{array}{c}\text { Age, } \\
\text { mean } \pm S D \\
\text { [years] }\end{array}$} & \multicolumn{2}{|c|}{$\begin{array}{l}\text { BSA, mean } \pm \text { SD } \\
{\left[\times 10^{-6} \mathrm{~m}\right]}\end{array}$} & \multicolumn{2}{|c|}{$\begin{array}{l}\text { Goitre incidence } \\
\text { (age-adjusted) [\%] }\end{array}$} & \multicolumn{4}{|c|}{$\begin{array}{l}\text { Goitre incidence Goitre incidence } \\
\text { BSA-adjusted) [\%] }{ }^{\mathrm{b}} \text { (age-adjusted) [\%] }\end{array}$} \\
\hline & Boys & Girls & & Boys & Girls & Boys & Girls & Boys & Girls & Boys & Girls \\
\hline \multirow[t]{2}{*}{1994} & \multicolumn{2}{|c|}{88} & $9.74 \pm 1.66$ & \multicolumn{2}{|c|}{$1.14 \pm 0.20$} & \multicolumn{2}{|c|}{92.6} & \multicolumn{2}{|c|}{95.4} & \multicolumn{2}{|c|}{66.7} \\
\hline & 42 & 46 & & $\begin{array}{c}1.14 \\
\pm 0.16\end{array}$ & $\begin{array}{c}1.13 \\
\pm 0.23\end{array}$ & 95.1 & 90 & 95.2 & 95.6 & 59 & 75 \\
\hline \multirow[t]{2}{*}{1999} & \multicolumn{2}{|c|}{207} & $9.69 \pm 2.35$ & \multicolumn{2}{|c|}{$1.17 \pm 0.26$} & \multicolumn{2}{|c|}{18.5} & \multicolumn{2}{|c|}{15.2} & \multicolumn{2}{|c|}{9.7} \\
\hline & 103 & 104 & & $\begin{array}{r}1.20 \\
\pm 0.29\end{array}$ & $\begin{array}{c}1.13 \\
\pm 0.22\end{array}$ & 18.1 & 18.8 & 12.2 & 17.8 & 10.8 & 8.5 \\
\hline \multirow[t]{2}{*}{2010} & \multicolumn{2}{|c|}{170} & $11.97 \pm 1.98$ & \multicolumn{2}{|c|}{$1.33 \pm 0.23$} & \multicolumn{2}{|c|}{15.8} & \multicolumn{2}{|c|}{11.6} & \multicolumn{2}{|c|}{4.4} \\
\hline & 80 & 90 & & $\begin{array}{c}1.37 \\
\pm 0.24\end{array}$ & $\begin{array}{c}1.29 \\
\pm 0.22\end{array}$ & 12 & 18.7 & 6.1 & 15.7 & 2 & 6.3 \\
\hline \multirow[t]{2}{*}{2016} & \multicolumn{2}{|c|}{138} & $10.23 \pm 1.51$ & \multicolumn{2}{|c|}{$1.24 \pm 0.20$} & \multicolumn{2}{|c|}{21.8} & \multicolumn{2}{|c|}{21.7} & \multicolumn{2}{|c|}{2.5} \\
\hline & 62 & 76 & & $\begin{array}{c}1.23 \\
\pm 0.20\end{array}$ & $\begin{array}{c}1.26 \\
\pm 0.21\end{array}$ & 20 & 25.5 & 20.7 & 22.2 & 5.7 & 0 \\
\hline
\end{tabular}

${ }^{a}$ Goitre incidence (age-adjusted) according to the reference values proposed by Zimmermann et al. [14], ${ }^{b}$ goitre incidence (BSA-adjusted) according to the reference values proposed by Zimmermann et al. [14], ' goitre incidence (age-adjusted) according to the reference values proposed by Szybiński et al. [15]. 


\section{Anthropometric data}

The height and the body mass of the children were measured using standard anthropometric techniques [10]. Children were measured without shoes and in light indoor clothing (each survey was performed at the beginning of the summer).

The heights were measured to the nearest millimetre with a Harpenden stadiometer, and the weights of children were recorded to the nearest $100 \mathrm{~g}$. Body surface area (BSA) was calculated from the following formula: $W t^{0.425} \times H^{0.725} \times 71.84$ $\times 10^{-4}$, where: $W t-$ weight $(\mathrm{kg}), \mathrm{H}-$ height $(\mathrm{cm})$.

\section{Urine iodine concentration (UIC)}

Urine samples were collected from each child, prior to the physical examination. Samples were stored at $-70^{\circ} \mathrm{C}$ until assay. In order to determine UIC, the modified catalytic method by Sandell and Kolthoff was used [11].

\section{Thyroid volume (V)}

Thyroid physical examination was performed, followed by ultrasound examination of the thyroid gland with a Siemens Sonoline SI-400 (1994 and 1999), Siemens Sonoline Prima (2010) and SonoScape S6 (2016) devices with 7.5 MHz linear array transducers. The examinations were carried out by two experienced ultrasound examiners (endocrinologists with many years of experience in performing thyroid ultrasound). The examination was performed in a supine position (the child was lying down on a medical coach). The sum of lateral thyroid lobe volumes (determined sonographically) constituted the actual volume of the

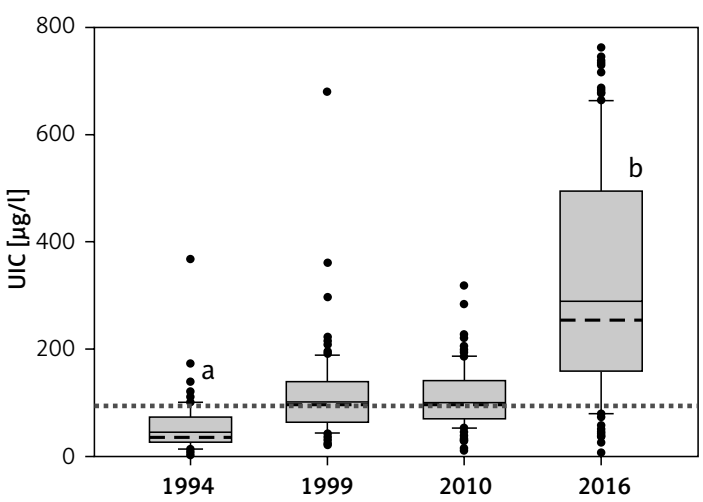

Figure 1. Urinary iodine concentration (UIC) in the examined children. Upper and lower limits of boxes are $75^{\text {th }}$ and $25^{\text {th }}$ percentiles, respectively. Horizontal dashed line and solid line in the boxes represent the median and mean values, respectively. Whiskers indicate standard deviation (SD). The horizontal red dotted line indicates a value of $100 \mu \mathrm{g} / \mathrm{l}$. Points represent a scatter of UIC results

${ }^{a} p<0.05$ vs. 1999, 2010 and 2016; ${ }^{b} p<0.05$ vs. 1999 and 2010. thyroid gland $(V)$; the volume of the isthmus was not included. The volume of the thyroid lobe was calculated according to the following formula, proposed by Brunn et al. [12]: $V\left(\times 10^{-6} \mathrm{~m}^{3}\right)=0.479 \times$ $W \times D \times L$, where $W=$ width $(\mathrm{cm}), D=$ depth $(\mathrm{cm})$, $L=$ length $(\mathrm{cm})$. We compared the volume of the thyroid gland $V\left(\mathrm{~m}^{3}\right)$ to BSA $\left(\mathrm{m}^{2}\right)$ by calculating $\mathrm{V} / \mathrm{BSA}$ ratio $\left(\mathrm{m} \times 10^{-6}\right)$. This ratio was proposed and used by us in our previous studies $[9,13]$. The obtained data were also compared to reference values for thyroid volume proposed by Zimmermann et al., adjusted for age and for BSA [14], as well as to reference values proposed by Szybiński et al., adjusted for age [15]. Only children aged 7-12 years and with BSA between 0.7 and $1.6 \mathrm{~m}^{2}$ were included in the analysis, as the standards were proposed only for those who met these criteria.

\section{Statistical analysis}

The data were statistically analysed using the nonparametric test for independent groups (Mann-Whitney rank sum test), Kruskal-Wallis one-way analysis of variance on ranks, followed by the Dunn test and $\chi^{2}$ analysis. In all analyses, statistical significance was accepted at the level of $p<0.05$. Data processing, statistical analyses, and figures were performed using SigmaPlot 12.3 (Systat Software, Inc., San Jose, CA, USA) and Excel (Microsoft Corp., Redmond, WA, USA).

\section{Results}

\section{Urine iodine concentration}

The median UICs were $45.5 \mu \mathrm{g} / \mathrm{l}$ (1994), $101.1 \mu \mathrm{g} / \mathrm{l}$ (1999), $100.6 \mu \mathrm{g} / \mathrm{l}$ (2010) and $288.3 \mu \mathrm{g} / \mathrm{l}$ (2016). The median value of UICs in 1994 was significantly lower in comparison to the other values. The median value of UICs in 2016 was significantly higher than the other values. The median values of UICS from 1999 and 2010 did not differ. The median UIC values are presented in Figure 1.

There were no statistically significant differences between the UIC median values in the group of girls and boys at each time point, and the values were, respectively, in 1994, 50.3 $\mu \mathrm{g} / \mathrm{l}$ vs. $39.2 \mu \mathrm{g} / \mathrm{l}$; in 1999, $104.5 \mu \mathrm{g} / \mathrm{l}$ vs. $97.3 \mu \mathrm{g} / \mathrm{l}$; in 2010, $100.1 \mu \mathrm{g} / \mathrm{l}$ vs. $105.9 \mu \mathrm{g} / \mathrm{l}$; and in 2016, $285.3 \mu \mathrm{g} / \mathrm{l}$ vs. $307.2 \mu \mathrm{g} / \mathrm{l}$.

The distribution of UIC is shown in Figure 2. The proportions of children, expressed as a percentage, in whom UIC was lower than $50 \mu \mathrm{g} / \mathrm{l}$ were: in $1994,59.1 \%$; in 1999, $12.6 \%$; in $2010,7.1 \%$; and in $2016,7.1 \%$. The proportions of children whose UIC was higher than $300 \mu \mathrm{g} / \mathrm{l}$ were in 1994, 1.1\%; in $1999,1.0 \%$; in $2010,0.6 \%$; and in $2016,47.9 \%$.

\section{Thyroid volume}

The size of the thyroid assessed by ultrasonography and presented as the V/BSA ratio was 


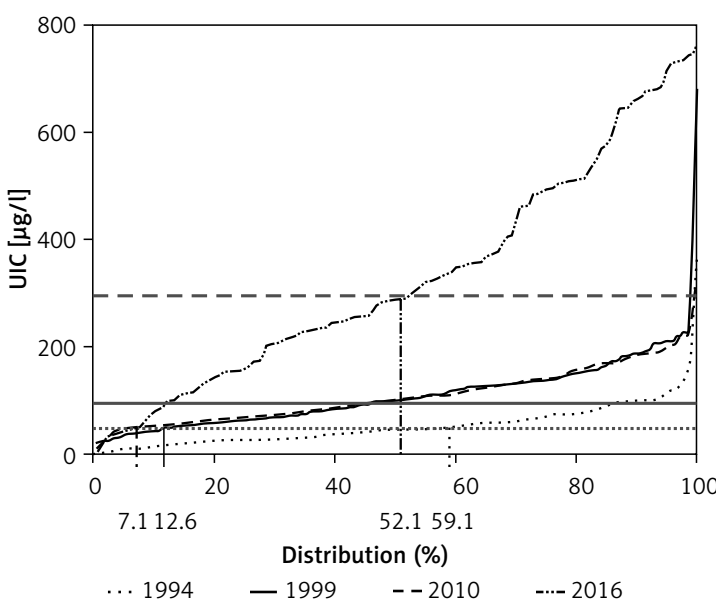

Figure 2. Distribution of urinary iodine concentration (UIC) in the examined children. Dotted line, solid line, dashed line and dashed-dotted line are distributions of UIC in years 1994, 1999, 2010 and 2016, respectively. The horizontal solid line, the horizontal dash line and the horizontal dotted line are values of $100 \mu \mathrm{g} / \mathrm{l}, 300 \mu \mathrm{g} / \mathrm{l}$ and $50 \mu \mathrm{g} / \mathrm{l}$ of UIC respectively. The percentage of children with UIC

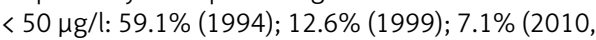
2016), as well as children with UIC > $300 \mu \mathrm{g} / \mathrm{l}-$ $52.1 \%(2016)$ is presented on the graph

$6.55 \times 10^{-6} \mathrm{~m}$ in 1994 and was higher than the V/BSA ratios at the next three time points, which were: in 1999, $2.73 \times 10^{-6} \mathrm{~m}$; in 2010, $2.73 \times 10^{-6} \mathrm{~m}$; and in $2016,2.70 \times 10^{-6} \mathrm{~m}$. Figure 3 shows the V/BSA values at particular time points with respect to sex.

It was found that V/BSA in girls was higher than in boys only in $2010\left(2.93 \times 10^{-6} \mathrm{~m}\right.$ vs. $2.59 \times$ $\left.10^{-6} \mathrm{~m}\right)$. At the remaining time points, V/BSA differences between girls and boys were not statistically significant and were: in 1994, $6.76 \times 10^{-6} \mathrm{~m}$ vs. $6.36 \times 10^{-6} \mathrm{~m}$; in $1999,2.87 \times 10^{-6} \mathrm{~m}$ vs. 2.71 $\times 10^{-6} \mathrm{~m}$; in $2016,2.78 \times 10^{-6} \mathrm{~m}$ vs. $2.68 \times 10^{-6} \mathrm{~m}$.

The goitre incidence calculated on the basis of the reference values proposed by Zimmermann et al. [14] was the highest in 1994 and was $92.6 \%$ and $95.4 \%$ (age- and BSA-adjusted, respectively) and was lower at the other time points: in 1999 , $18.5 \%$ and $15.2 \%$; in $2010,15.8 \%$ and $11.6 \%$; and in 2016, 21.8 and $21.7 \%$.

The goitre incidence, calculated on the basis of the reference values proposed by Szybiński et al. [15], was also the highest in 1994 and was 66.6\% (in girls and boys $75 \%$ and $59 \%$ respectively); in 1999, 9.7\% (8.5\% and 10.8\%); in 2010, 4.4\% (6.3\% and $2 \%$ ); and in 2016, 2.5\% (0 and 5.7\%). The values of goitre incidence are presented in Table I.

\section{Discussion}

The present results show that after introduction of iodine prophylaxis, the iodine intake in the studied population increased continuously. The value of median UIC in $1994(45.5 \mu \mathrm{g} / \mathrm{l})$ cor-

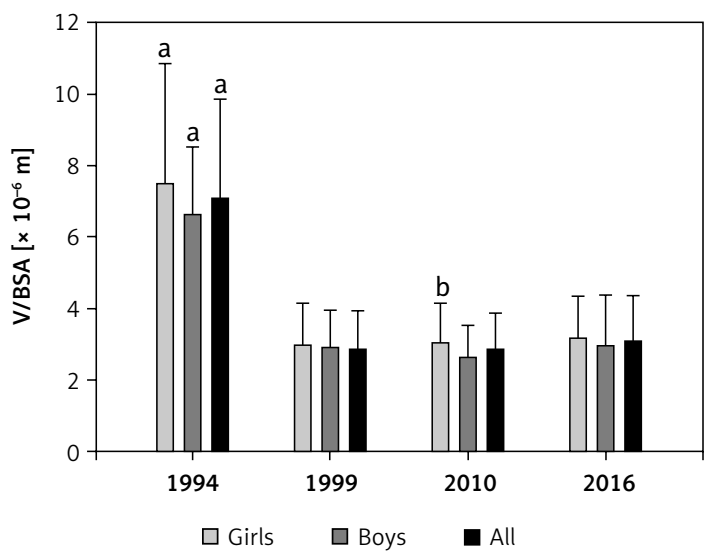

Figure 3. Ratio of thyroid volume $(\mathrm{V})\left[\times 10^{-6} \mathrm{~m}^{3}\right]$ to body surface area (BSA) $\left[\mathrm{m}^{2}\right]$ in examined children - V/BSA

Whiskers indicate standard deviation (SD). ${ }^{a} p<0.05$ vs. 1999, 2010 and 2016; ${ }^{b} p<0.05$ vs. boys in 2010.

responded to moderate iodine deficiency, while median values after iodine prophylaxis (1999 -

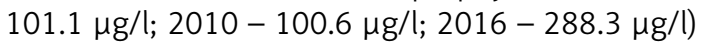
corresponded to adequate values; however, the last value (2016) was markedly higher than the previous two, being close to the upper limit of UIC accepted as normal [16]. The obtained results are consistent with other studies evaluating the supply of iodine in Poland $[17,18]$. Thus, Poland has become a country where iodine intake should be considered sufficient [19].

Although the median values of UICs in 1999 and 2010 do not differ, the distribution of iodine supply has changed for the better (the percentage of UIC $<50 \mu \mathrm{g} / \mathrm{l}$ dropped from $12.1 \%$ in 1999 to $7.1 \%$ in 2010). These data not only prove the effectiveness of iodine prophylaxis, but they also show a more homogeneous increase in iodine supply in the studied population. The analysis of the prevalence of goitre is also evidence of longer-lasting, increased iodine supply. While in 1999 the percentage of goitre was $9.7 \%$ according to the reference values defined by Szybiński et al. [15] (which corresponded to mild iodine deficiency), the analysis of goitre incidence at subsequent time points proved that goitre was no longer considered endemic (4.4\% and $2.5 \%$ in 2010 and 2016, respectively). The obtained data indicate that drawing conclusions on the iodine supply, based only on median UIC values, is insufficient, especially during the transition period, i.e. after the introduction of a new iodine prophylaxis model. During this period, the diet of many people remains almost the same as before, so it may take several months or even years until the iodine supply improves.

While the use of the reference values proposed by Szybiński et al. [15]. correlates relatively well with the iodine supply in the studied population, the goitre analysis according to the reference val- 
ues proposed by Zimmermann et al. [14], under the auspices of the WHO, is not a useful tool. Results obtained in this way (Table I) erroneously suggest that there is still goitre endemicity in the study population. The fact that the reference data were developed based on examinations carried out in a supine position may be the possible cause of this inconsistency [14, 20, 21]. Such a discrepancy may also result from different methods of measurement and associated inter-observer and intra-observer errors [20].

Use of the V/BSA ratio is a much better method for analysing changes in thyroid size [13]. The V/BSA value was the highest in 1994 and decreased significantly after the introduction of iodine prophylaxis. There were no statistically significant differences between 1999 and 2010, and 2016 (despite statistically significant differences among the UIC values). This proves that only iodine deficiency (1994) leads to enlargement of the thyroid gland and consequently to goitre formation. The adequate iodine supplies, varying either around the minimum normal values (median UIC: $101.1 \mu \mathrm{g} / \mathrm{l}$ in 1999; $100.6 \mu \mathrm{g} / \mathrm{l}$ in 2010), or around the maximum normal values (median UIC: $288.3 \mu \mathrm{g} / \mathrm{l}$ in 2016), do not have a significant effect on thyroid size. It should be stressed that the last, highest value (2016) was associated with no iodine-induced adverse signs or symptoms.

Our present data concerning UICs in school-aged children in 2016, which probably correspond to a markedly increased iodine intake, are quite surprising. It is worth noting that in 2016 the proportion of children with UIC above $300 \mu \mathrm{g} / \mathrm{l}$ increased significantly $-47.9 \%$ vs. $0.6 \%$ (2010), $1.0 \%$ (1999) and $1.1 \%$ (1994). It is difficult to explain these findings exclusively by an increase in consumption of iodized salt in the population. On the contrary, for many years in Poland, as in other countries, multidirectional measures to reduce dietary salt intake have been observed [22]. The average salt intake in Poland at the time of the introduction of iodine prophylaxis was $15 \mathrm{~g} /$ day [23], whereas currently the goal is to reduce the intake of $\mathrm{NaCl}$ in the general population to less than $5 \mathrm{~g}$ /day [24]. Such systematic reduction of salt intake as an iodine carrier has raised fears that Poland, particularly in the face of iodine supply being close to the minimum normal values (1999, 2010), could again become a country with iodine deficiency [25]. The reappearance of iodine deficiency has, in the past, already affected several countries, such as Australia [26]. On the other hand, the results of our studies (2016) are consistent with the results of studies on iodine supply in the Slovak population (median of UIC was $140-320 \mu \mathrm{g} / \mathrm{l}$ depending on the study group) [27], whose iodine prophylaxis is based on a model very similar to the Polish one (obligatory consumption of iodized salt, containing $25 \mathrm{mg} \mathrm{KI} / \mathrm{kg}$ of $\mathrm{NaCl}$ or equivalent iodine value in the form of $\mathrm{KIO}_{3}$ ), and the type of diet in both countries is also similar. The diversification of iodine sources may be the possible explanation of the obtained results. At the time of introduction of iodine prophylaxis, there were few alternative sources of iodine. At present, drinking water containing iodine, most commonly at a concentration of $0.1-0.2 \mathrm{mg} / \mathrm{l}$, is being consumed more and more frequently [25].

The relatively narrow range of potential intake is an advantage of salt as an iodine carrier, since salt as a spice is only an additive to consumed food. For other basic iodine-containing food products (including water, milk or meat), the range of their potential intake increases significantly, which may lead to iodine intake at doses much higher than recommended (e.g. consuming a large amount of drinking water containing iodine during hot days and/or during physical activity).

Interestingly, some of the medical mineral waters contain more iodine (e.g. Franciszek water deriving from the spa town of Wysowa-Zdroj (southern Poland close to the border with Slovakia) contains $2.9 \mathrm{mg}$ of $\mathrm{I} / \mathrm{l}$, and Henryk water from the same spa town contains $0.9 \mathrm{mg}$ of $\mathrm{I} / \mathrm{l}$ ) [28]. Consuming them according to the manufacturer's general recommendations $(200 \mathrm{ml} 2-3$ times a day), for prevention of various diseases, corresponds to $1,160-1,740 \mu \mathrm{g}$ of I/day. In the case of medical recommendations, water consumption can be even greater. However, it seems very unlikely that the potential consumption of the above-mentioned mineral waters could be considered as a reason for the UIC values obtained by us in 2016, because the distribution of these waters is markedly limited in Poland not only due to high iodine anion concentrations but also because of very high content of sodium cations.

Another example of additional sources of iodine in Poland is the iodination of animal food, which consequently results in the phenomenon that milk, milk products and meat are becoming year by year richer sources of iodine for humans [23]. It is worth adding that some products containing iodine (e.g. mineral drinking water) are actively advertised as "healthy food", and in the Polish population there is still a belief that Poland is a country of iodine deficiency (hence many people choose the seaside as a destination of their vacation, thus increasing iodine intake with inhaled air).

The processes of integration between countries and the free flow of people and goods are also of great importance for iodine supply in the population. Food (especially imported by individuals) does not need to meet the standards of iodine content set by a country, because models of iodine prophylaxis usually differ in different countries.

In conclusion, it may be concluded that iodine prophylaxis is not an event, but a process that 
changes over time; thus the key to the permanent elimination of iodine deficiency is the monitoring of this process and its modification, depending on the changing conditions.

The iodine prophylaxis introduced in 1997 has proved to be effective in eliminating iodine deficiency in the studied population, which, together with the data from other studies, shows that Poland has become a country with an adequate iodine supply. The diversification of iodine sources, despite the reduction of salt consumption, has led to an increase in iodine supply in the population of school-aged children, expressed as the UICs close to the upper limit of values considered normal. Further increase in iodine supply, particularly uncontrolled, may be unfavourable for health; therefore constant and active monitoring of iodine prophylaxis is required to ensure optimum iodine intake.

\section{Acknowledgments}

This study was supported by statutory funds from the Polish Mother's Memorial Hospital Research Institute and the Medical University of Lodz (503/1-107-03/503-11-001), Lodz, Poland.

\section{Conflict of interest}

The authors declare no conflict of interest.

\section{References}

1. Delange F. lodine deficiency in Europe and its consequences: an update. Eur J Nucl Med Mol Imaging 2002; 29 (Suppl 2): S404-16.

2. Szybiński Z, Żarnecki A. Prevalance of goiter, iodine deficiency and iodine prophylaxis in Poland. The results of nation-wide study. Endokrynol Pol 1993; 44: 373-88.

3. Szybiński Z, Lewiński A. Statement of the Polish Council for Control of lodine Deficiency Disorders, Executive Committee of the Polish Society of Endocrinology and the Team of National Medical Consultant in the field Endocrinology on the issue of food supplementation with iodine [Polish]. Endokrynol Pol 1996; 47: 96-7.

4. Regulation of the Minister of Health and Social Welfare of 24 July 1996 on prohibition of production and marketing of certain types of salt for consumption [Polish]. Monitor Polski 1996; Nr 48, poz. 462.

5. Disposition of the Minister of Health of 19 December 2002 on enriching substances added to food and conditions of their use. Dziennik Ustaw 2003; Nr 27, poz. 237.

6. Karbownik-Lewinska M, Stepniak J, Milczarek M, Lewinski A. Protective effect of $\mathrm{KI}$ in $\mathrm{mtDNA}$ in porcine thyroid: comparison with $\mathrm{KIO} 3$ and nDNA. Eur J Nutr 2015; 54: 319-23.

7. Delange F, Benker G, Caron P, et al. Thyroid volume and urinary iodine in European schoolchildren: standardization of values for assessment of iodine deficiency. Eur J Endocrinol 1997; 136: 180-7.

8. Szybinski Z, Delange F, Lewinski A, et al. A programme of iodine supplementation using only iodised household salt is efficient - the case of Poland. Eur J Endocrinol 2001; 144: 331-7.

9. Zygmunt A, Adamczewski Z, Wojciechowska-Durczyńska K, et al. Evaluation of efficacy of iodine prophylaxis in Poland based on the examination of schoolchildren living in Opoczno Town (Lodz Voivodship). Thyroid Res 2012; $5: 23$.

10. World Health Organization. Physical status: the use and interpretation of anthropometry. Report of a WHO Expert Committee. World Health Organ Tech Rep Ser 1995; 854: 1-452

11. Sandell EB, Kolthoff IM. Microdetermination of iodine by catalytic method. Microchim Acta 1937; 1: 9-25.

12. Brunn J, Block U, Ruf G, Bos I, Kunze WP, Scriba PC. Volumetric analysis of thyroid lobes by real-time ultrasound. Dtsch Med Wochenschr 1981; 106: 1338-40.

13. Zygmunt A, Zygmunt A, Karbownik-Lewińska M, Lewiński A. Can thyroid size still be considered as a useful tool for assessing iodine intake? Ann Agric Environ Med 2015; 22: 301-6.

14. Zimmermann MB, Hess SY, Molinari L, et al. New reference values for thyroid volume by ultrasound in iodine-sufficient schoolchildren: a World Health Organization/Nutrition for Health and Development Iodine Deficiency Study Group Report. Am J Clin Nutr 2004; 79: 231-7.

15. Szybiński Z, Trofimiuk-Müldner M, Buziak-Bereza M, Walczycka L, Hubalewska-Dydejczyk A. Reference values for thyroid volume established by ultrasound in Polish schoolchildren. Endokrynol Pol 2012; 63: 104-9.

16. WHO/UNICEF/ICCIDD. Assessment of Iodine Deficiency Disorders and Monitoring their Elimination. A Guide for Programme Managers. World Health Organization WHO, Geneva 2008.

17. Baczyk M, Ruchała M, Pisarek M, et al. lodine prophylaxis in children population on the Wielkopolska Region area from year 1992 to 2005. Endokrynol Pol 2006; 57: 110-5

18. Słowińska-Klencka D, Popowicz B, Lewiński A, Sporny S, Klencki $M$. The fine-needle aspiration biopsy efficacy of small thyroid nodules in the area of recently normalized iodine supply. Eur J Endocrinol 2008; 159: 747-54.

19. Global Scorecard of lodine Nutrition in 2017 in the general population and in pregnant women (PW). lodine Global Network. http://www.ign.org/cm_data/ IGN_Global_Scorecard_AllPop_and_PW_May2017.pdf Accessed 1 June 2017.

20. Zygmunt A, Adamczewski Z, Zygmunt A, KarbownikLewinska M, Lewinski A. The influence of the manner of performing the thyroid ultrasound examination on the reliability of the assessment of the thyroid size in school-aged children. Horm Res Paediatr 2017; 87: 368-76.

21. Abd El Naser Yamamah G, Kamel AF, Abd-El Dayem S, Hussein AS, Salama $H$. Thyroid volumes and iodine status in Egyptian South Sinaischoolchildren. Arch Med Sci 2013; 9: 548-54.

22. EU position and commitment in advance of the UN high-level meeting on the prevention and control of non-communicable diseases. European Parliament resolution of 15 September 2011 on European Union position and commitment in advance to the UN high-level meeting on the prevention and control of non-communicable diseases. Official Journal of the European Union. 2013/C51E/20. http://eur-lex.europa.eu/LexUriServ/ LexUriServ.do?uri=OJ:C:2013:051E:0130:0137:EN:PDF Accessed 1 June 2017. 
A. Zygmunt, Z. Adamczewski, K. Wojciechowska-Durczynska, K. Krawczyk-Rusiecka, E. Bieniek, M. Stasiak, A. Zygmunt, K. Purgat, R. Zakrzewski, J. Brzezinski, M. Karbownik-Lewinska, A. Lewinski

23. Szybiński Z, Jarosz M, Hubalewska-Dydejczyk A, et al. lodine-defciency prophylaxis and the restriction of salt consumption - a $21^{\text {st }}$ century challenge. Endokrynol Pol 2010; 61: 135-40.

24. Mancia G, Fagard R, Narkiewicz K, et al.; Authors of the Task Force members. Practice guidelines for the management of arterial hypertension of the European Society of Hypertension (ESH) and the European Society of Cardiology (ESC): ESH/ESC Task Force for the Management of Arterial Hypertension. J Hypertens 2013; 31: 1281-357.

25. Lewiński A, Zygmunt A. lodine prophylaxis in Poland new, old challenges. Ann Agric Environ Med 2014; 21: $1-4$.

26. World Health Organization. Salt reduction and iodine fortification strategies in public health: report of a joint technical meeting, convened by World Health Organization and The George Institute for Global Health in collaboration with the International Council for the Control of lodine Deficiency Disorders Global Network, Australia, March 2013. World Health Organization, Geneva 2014.

27. Podoba J, Racova K, Urbankova H, Srbecky M. Current status of iodine deficiency-related disorders prophylaxis in Slovakia - the life's work of Julian Podoba remained unfinished. Endocr Regul 2016; 50: 3-9.

28. Healing water from Wysowa-Zdroj - leafet [Polish]. http://img.iap.pl/s/153/202087/Edytor/File/lecznicze. pdf. Accessed 1 June 2017. 